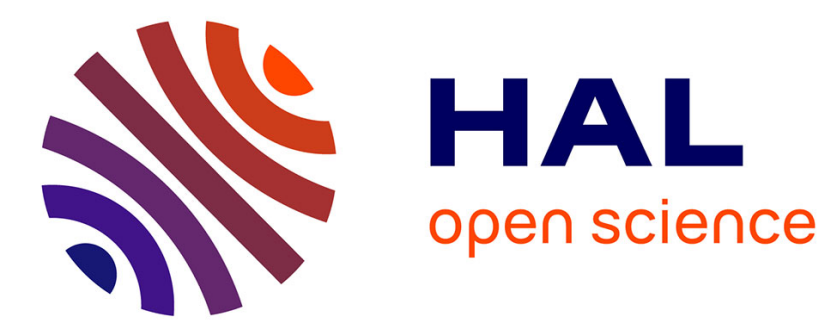

\title{
Numerical analysis of nonhomogeneous media through photothermal deflection method
}

M. Bertolotti, M. Firpo, A. Fontana, G. Liakhou, R. Li Voti, C. Sibilia, G. de Portu

\section{- To cite this version:}

M. Bertolotti, M. Firpo, A. Fontana, G. Liakhou, R. Li Voti, et al.. Numerical analysis of nonhomogeneous media through photothermal deflection method. Journal de Physique IV Proceedings, 1994, 04 (C7), pp.C7-83-C7-86. 10.1051/jp4:1994721 . jpa-00253249

\section{HAL Id: jpa-00253249 https://hal.science/jpa-00253249}

Submitted on 1 Jan 1994

HAL is a multi-disciplinary open access archive for the deposit and dissemination of scientific research documents, whether they are published or not. The documents may come from teaching and research institutions in France or abroad, or from public or private research centers.
L'archive ouverte pluridisciplinaire HAL, est destinée au dépôt et à la diffusion de documents scientifiques de niveau recherche, publiés ou non, émanant des établissements d'enseignement et de recherche français ou étrangers, des laboratoires publics ou privés. 
Numerical analysis of nonhomogeneous media through photothermal deflection method

\author{
M. Bertolotti, M. Firpo, A. Fontana, G. Liakhou, R. Li Voti, C. Sibilia and G. De Portu* \\ Dipartimento di Energetica, Università di Roma "La Sapienza", Via Scarpa 16, 00161 Roma, Italy \\ * C.N.R. IRTEC-Faenza, Italy
}

\begin{abstract}
A numerical analysis founded on the analog circuit model is applied to describe (surface or volume) defects and nonhomogeneities in materials, which can be detected through the Photothermal Deflection Method. Experimental results are also discussed.
\end{abstract}

\title{
1. INTRODUCTION
}

The mirage technique has been proved to be very useful for nondestructive characterization of materials and layered structures, as for instance the detection of shallow buried defects ${ }^{1,2}$. In the present paper a numerical analysis of the photothermal deflection signal in an opaque material with defects is discussed. The Finite Difference Method (FDM) ${ }^{3}$ is applied to solve the Fourier heat conduction equation, using the "7 -points - 3D molecule model" suitably optimized so that different kinds of nonhomogeneities can be studied, including cracks, bubbles if the thermal parameters and the volume dimension of the 3D grid is well set. The basic condition is that the finite dimension of the nonhomogeneity should be larger than the distance of the grid points. A 3D temperature distribution has been calculated, as well as photodeflection signal in its normal and lateral components.

A good agreement between experimental results and the numerical analysis is shown for the photodeflection angle in the case of a zirconate ceramic suffering a rectangular indentation.

\section{NUMERICAL MODEL}

The Finite Difference Method (FDM) ${ }^{3}$ has been applied to solve the nonhomogenous heat conduction equation. The " forward time centered space " algorithm has been used to solve the temperature distribution problem at a given time. The material has been modeled with the help of the "7 -points - 3D molecule model" which assures a good accuracy.

Therefore the sample has been described by a 3D grid; each point of the grid is associated to a finite volume $\Delta \mathrm{X} \Delta \mathrm{Y} \Delta \mathrm{Z}$ small enough to consider approximately constant the temperature and 
the main thermal and optical properties (thermal conductivity, diffusivity and optical absorption) In this way a volume defect can be modeled as a volume of thermophysical properties different from the matrix.

In order to increase the accuracy of the algorithm also in the case of samples with a small spatial scale of nonhomogeneities, the problem of the discontinuities between regions with different thermo-physical properties, has been solved by using the electrical analog circuit model. In this way the thermal conductivity, which should exhibit a discontinuity in different regions is described by an " effective " value: $K_{\text {eff }}$

$$
K_{e f f}=\frac{K_{1} * K_{2}}{K_{1}+K_{2}}
$$

where $K_{1}$ and $K_{2}$ are the thermal conductivities of two close regions; between these regions the flux continuity condition has been used. With the electrical analog circuit model the thermal flux plays the role of the electrical current and the temperature increase plays the role of the voltage.

The source term ( heat power density related to the pump laser source ) has been considered not only as a boundary condition at the air - material interface, but it is present inside the material due to the finite value of the electromagnetic absorption.

The " absorption boundary conditions " have been used to avoid any thermal reflection from the numerical boundaries, while at the air-material interface the flux continuity has been considered.

The developed software is able to follow the temperature dynamics at the surface and in any position inside the material, for homogeneous and non homogeneous materials.

Fig.1a shows an example of the calculated temperature profile at the surface after $7 \mathrm{~ms}$ of irradiation of a time modulated gaussian heating source, when the surface of the material has suffered a rectangular indentation with a size of $\cong 200 \mu \mathrm{m}$, and depth of $200 \mu \mathrm{m}$ as shown in Fig. 1b. The area investigated in fig. $1 \mathrm{a}$ is about $820 \mu \mathrm{m} \times 820 \mu \mathrm{m}$ being the distance between two adjacent point $20 \mu \mathrm{m}$. The laser (pump beam is an Ar laser) is placed at the center of the indentation (see fig.1b). The considered material is a zirconate ceramic whose thermal parameters are $D$ (thermal diffusivity) $=0.01 \mathrm{~cm}^{2} / \mathrm{s}, \mathrm{K}$ ( thermal conductivity) $0.2 \mathrm{~W} / \mathrm{cm}^{\circ} \mathrm{K}, \mathrm{c}$ ( specific heat ) $=0.46 \mathrm{~J} / \mathrm{gr}^{\circ} \mathrm{K}, \rho$ (density) $=6.08 \mathrm{gr}^{\circ} \mathrm{cm}^{3}$, the optical absorption was $10^{3} \mathrm{~cm}^{-1}$.

\section{EXPERIMENTAL SETUP}

The photodeflection method used in its transverse configuration. The pump beam was a focused Ar laser (Power IW) time modulated by a mechanical chopper. The probe beam was an $\mathrm{He}-\mathrm{Ne}$, traveling close to the material surface. The detection of the probe signal was performed through a position sensor. Probe beam scan of the material has been controlled by computer. In Fig. 2 the comparison between experimental results and numerical analysis is shown for the photodeflection probe signal as a function of the lateral offsets between pump and probe in the case of a zirconate ceramic. The frequency of the mechanical chopper is $\mathrm{f}=16 \mathrm{~Hz}$. The Pump beam size which is focused into the indentation, is about $80 \mu \mathrm{m}$.

It is interesting to observe that the signal does not go to zero for large offsets, and several maxima and minima are present, mainly associated to the compression of the material and the presence of vertical cracks around the indentation.

Several measurements have been performed also changing the position of the pump with respect to the indentation. Work is in progress to put into evidence numerically these effects . 


\section{CONCLUSIONS}

A numerical method to detect defects and cracks present in a material have been studied. This method is able to foltow the temperature dynamics and the photodeflection signal when nonhomogenities of the material over or under the surface are present. Numerical experiments, devoted to put into evidence the role of the cracks around a surface indentations are in progress.

\section{REFERENCES}

1 - P.K.Kuo, L:D. Favro, R.L. Thomas in "Photothermal Investigation of Solids and fluids " Ed.J.A.Sell , (Academic Press 1989) pp 191-212.

2 - J.P.Roger, D.Fournier, A.C. Boccara, F.Lepoutre , J.Physique Col C5 (1989) 295-310.

3 - J.Rantala ,J.Hartikainen,J.Jaarinen - Appl.Phys 50 (1990) 465 -471.
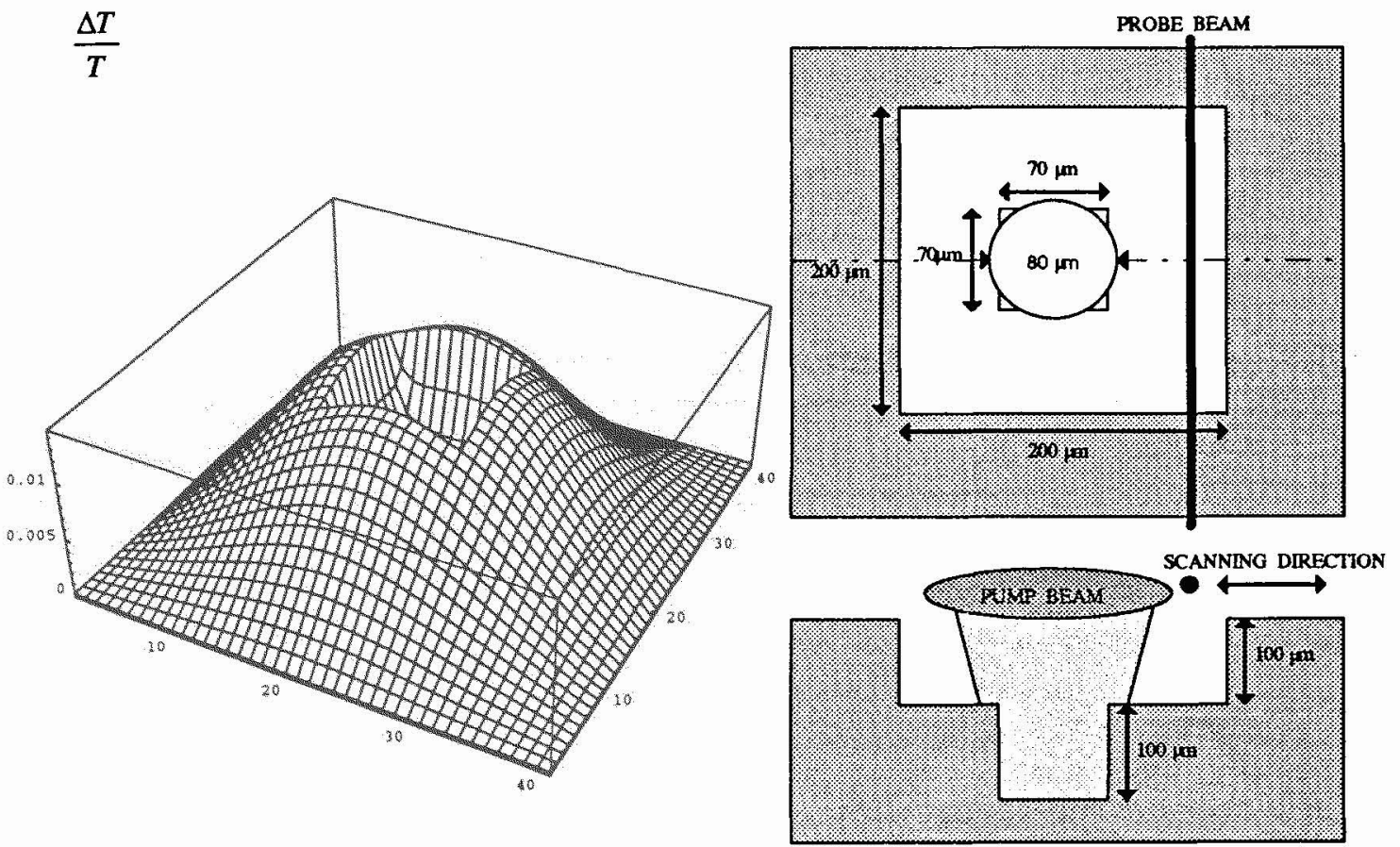

Fig. 1a -Temperature distribution at the surface of a zirconate ceramic after $7 \mathrm{~ms}$. Fig. 16 geometrical configuration 


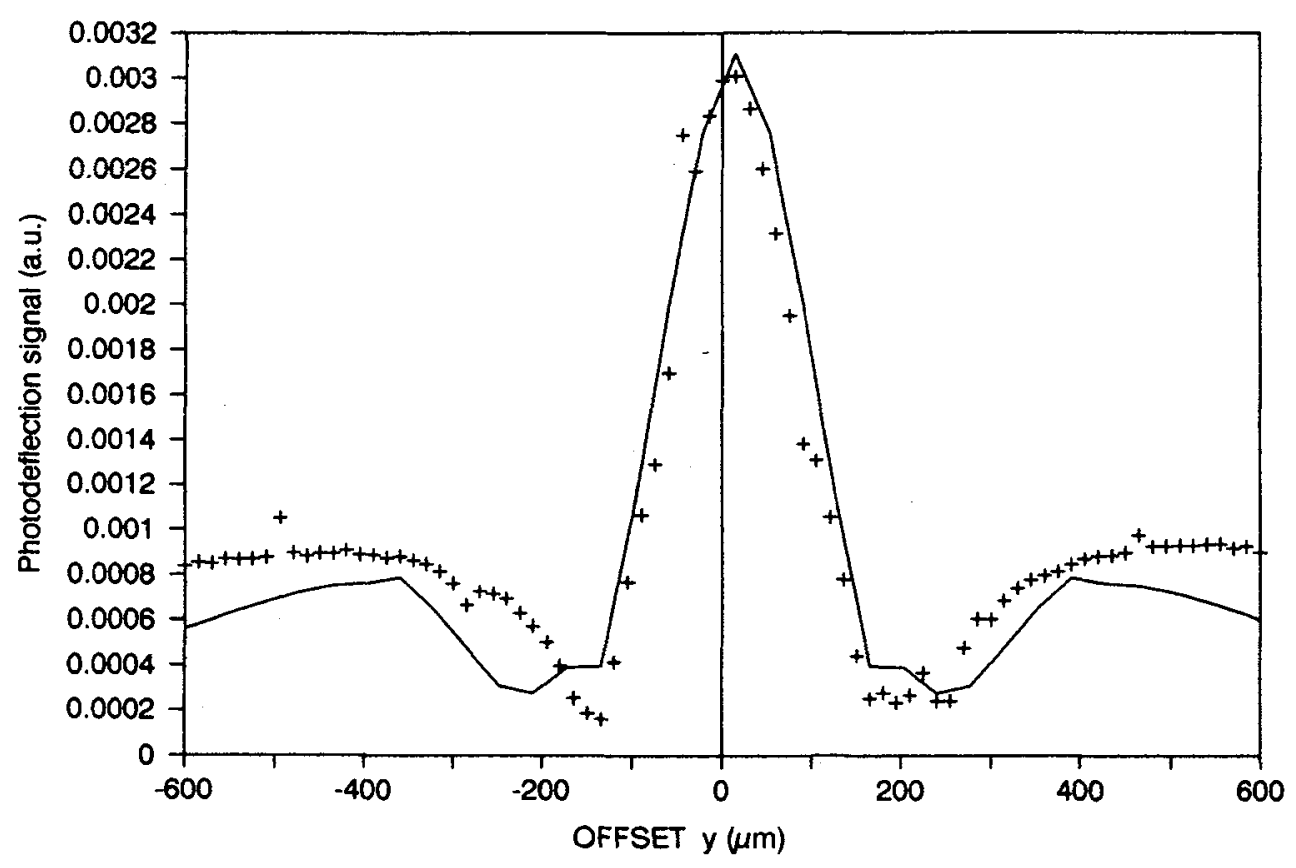

Fig. 2 Comparison between experimental results and numerical analysis for the photodeflection signal (transverse config., normal component) as a function of the pump probe offset for frequency $\mathrm{f}=16 \mathrm{~Hz}$ in the case of a zirconate ceramic material with a rectangular surface damage: cont line) numerical analysis, +) experimental results. 